\title{
Shaping social beliefs: A community sensitive health information system for rural India
}

\author{
Vikram Parmar, David V Keyson and Cees deBont \\ Social and Contextual Interaction Design \\ Faculty of Industrial Design \\ Delft University of Technology
}

\begin{abstract}
This paper presents critical issues concerning the community sensitive personal health information system in rural India, from an industrial design perspective. Literature in current ICT based applications, point to the fact that, current efforts related to personal health information dissemination have gained limited acceptance at community level among rural population. This is probably due to limited understanding of community sensitive information needs, societal structure and user beliefs of the rural community. To understand the underlying social values and users beliefs related to personal health information ( $\mathrm{PHI}$ ), a preliminary study including field interviews and review of currently deployed ICT projects was conducted. This paper presents the preliminary results, indicating several social and design challenges towards the development of a PHI system. Further the paper proposes a design framework, which includes design as a primary tool to shape existing user beliefs to positively influence the technology acceptance process of PHI system.
\end{abstract}

Keywords: Personal health, Community behavior, Information distribution

\section{Introduction}

In rural India, the delivery of relevant personal health information and medical treatment is still recognized as a large challenge for government and private sectors $[1,2]$. At the government level, efforts to disseminate PHI and medical treatments currently occur at three levels (Figure-1). In particular, the role of Primary Healthcare Center (PHC) is to run outreach programmes, organize health awareness and treatment camps in villages which falls under their vicinity. However the government health care reach-out programmes have not been able to keep up with the growing health care demands in villages. The partial success of government healthcare system could be attributed to large geographical distances between urban and rural areas, limited medical staff, and poor infrastructure to accommodate new medical schemes from pharmaceutical companies. 
Towards supporting government health initiatives, several external efforts from non government organization and multinational companies have been initiated. These initiatives involve organizing health camps with private hospitals, distributing free medicines, and use of information and communication technology to provide distant healthcare or tele-medicine facilities.

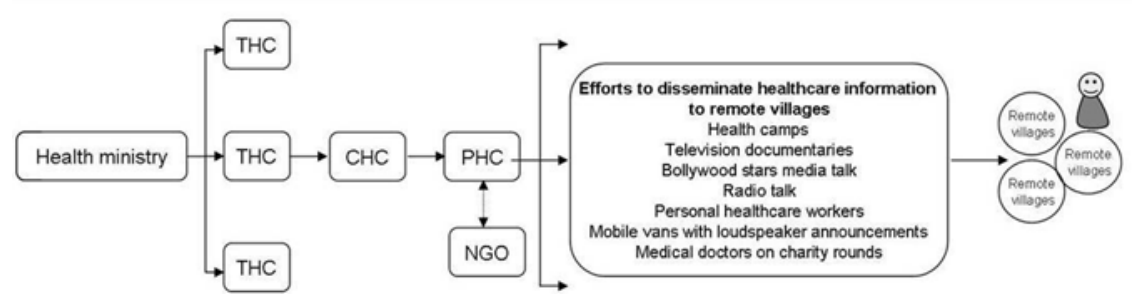

Fig. 1. Existing Public Health Information Efforts

\subsection{Need of PHI system}

Currently, the ICT health related applications offered at tele-centers or on PDA platforms tends to focus on disease treatment related information, rather than providing insight on prevention. The advances of health care in the diagnosis and treatment may have helped add years to users life, but have not yet rendered the community at large, healthier. This situation clearly indicates the need to educate the rural communities towards having a better understanding of disease and their basic preventive measures. For instance, in India every year 500,000 children under age five die due to diarrhea [3]. Precautionary measures such as feeding oral rehydration salts in the primary stage of illness could save few lives. To educate rural users information system are needed which could nurture knowledge among villagers, such that their personal health can be improved via their own initiative and efforts. Here, an information system could be defined as a tool to offer relevant information to rural users and involves network of all communication comprised of people, machines and methods to collect, process, transmit and disseminate data $[4,5]$.

Despite several ICT efforts such as tele-centers or use of PDA platforms to reach remote villages with limited healthcare facilities eg teledoc, which offers distance diagnosis, the acceptance of ICT based healthcare applications in rural India has been limited. This situation could be partially attributed to limited understanding of rural societal structure and attitude of rural users towards personal health issues. In reviewing the societal structure of rural areas, strong hierarchy at work and home environment, male dominance in decision making at home, orthodox religious practices and overall low awareness about global development was identified. Furthermore, field interviews revealed that, due to stigmatization, women in rural areas finds it difficult to access appropriate healthcare. Stigmatization is based on an existing social values and beliefs, which are the outcome of existing close mindset, and superstition owing to religious practices [6]. A study by Spector [7, 8] stated 
that, ignorance of these culturally divergent beliefs and traditional health care practices may lead to failure of health information systems. In addition, issues such as lack of privacy to share and receive information related to personal health care are inhibiting the acceptance of PHI systems. A study by Dourish \& Anderson [9] noted that privacy concerns are not something that can be retrofitted to technologies, but are fundamental to their structure and usage models.

In above context, to accentuate ICT as a mass media information tool, the information needs related to existing community thinking, social values and beliefs should be considered as fundamental issues in developing PHI systems. This should result in an acceleration of acceptance of the knowledge sharing mechanisms to improve the well being of the community. Furthermore, Byrne \& Sahay [10] pointed out that there is a need to reconfigure the existing individual based approach where information is only received or delivered to one or two users via PHI systems to a community- sensitive approach where maximum number of users could be reached. In order to investigate the above issues from an industrial design perspective, the paper aims to present preliminary findings about existing inhibiting factors in rural communities with specific reference to personal hygiene issues concerning rural women and factors influencing the acceptance of PHI systems. These inhibiting factors have been explained as an outcome of field interviews and review of ICT based case studies in rural India. The paper concludes with proposed research approach towards shaping the social beliefs for developing community sensitive personal health information system.

\section{Current Study}

The current research is a part of on-going doctoral research at the Industrial Design Department in Delft, The Netherlands. In reviewing the ICT literature, rich data on development of information systems for developing countries capturing multiple view-points from various fields of discipline was reviewed. For instance in social anthropology Metcalfe \& Joham [11] described their research on oral culture, and have argued that modern technology, such as UHF citizen band radio, can be highly effective in supporting knowledge exchange between groups with a strong oral tradition. From the view-point of information infrastructure Rolland \& Monterio [12] addressed the standardization versus localization debate, and argued that universal solutions are unlikely to be successful in multiple location spanning different social, political, institutional and strategic context. From a knowledge management framework, Okunoye \& Karsten [13] provided a detailed discussion of the specific use of technologies such as e-mail, database, and telecommunications in six African countries to access knowledge sources. However, there is a lack of body of knowledge in literature on the correlation between design and social cultural issues involving the social process of groups, communities and societies. Furthermore, how design can be used as a research tool towards developing community sensitive information systems needs to be researched. To address the above gap in literature the research reported here presents an industrial design approach to research on underlying socio-cultural issues in rural context towards developing personal health information systems. 
The study intends to build design approach by integrating components from "Community organization framework by Kenny,S [14]. This includes the Activist's framework involving: community participation, social change, advocacy and self determination. In particular, the current study will focus on social change, which occurs at three levels- structural (entrust decision making structures to facilitate community self determination), ideational (participants begin to understand their interdependence and the values of mutuality and compassions), level of skills (where citizens become skilled in participating and articulating concerns identifying needs and resolving conflicts). In collaboration with non government organization, the project will be piloted in western India.

\section{Method}

To understand the role of ICT in personal health, users social values, and their perceptions about new technology development, two research methods were applied: structured and unstructured field interviews and case study research method advocated by $Y$ in, $R$ [15]. The interviewing team included an industrial designer in conjunction with local NGO employees. Note: To narrow the scope of current research and test the proposed design process, personal hygiene problems related to village women and girls has been undertaken as a problem case.

\subsection{Structured and unstructured field interviews}

The structured and unstructured field interviews of (n-20) villagers and (n-20) ICT service providers assisted in developing a qualitative assessment of (a) demographic data, (b) daily routine and schedules, (c) existing social system and traditional beliefs (c) current practices and efforts to access health information (d) user ICT exposure and their perceptions about new technology (e) identify the information needs and different user segments, and (f) ICT success and failures in villages.

\subsection{Review of cases}

To establish a broader understanding of the existing ICT success and failures, in addition to ICT based health care projects, one e-governance was also reviewed. Being one of the initial e- projects in India, these projects were evaluated to gain empirical evidence from their design and deploying experiences. A brief explanation about selected projects is given below:

Tele-doc [16]: It is an e-health programme offering door to door medical service. The health care information is delivered by village based field worker, who records and transmits diagnostic data to an IT enabled central clinic via java enabled mobile telephone.

Electronic Medical Record (EMR) [17]: Mainly involves collecting data for better understanding of disease pattern in a community, which could lead to optimal 
resource allocation during outbreak. The information is recorded via a hand held device.

$\mathbf{N}$-logue [18, 19]: Offers distant health care in the area such as cardiac care, remote patient monitoring and veterinary care. An information transaction relies on $35 / 70$ kbps internet connection.

Gyandoot [20] : Is an intranet based Government to Citizen (G2C) service delivery portal offering twenty two applications namely agro-market Information, Income Certificate, Domicile Certificate, Caste Certificate etc. The gyandoot centers are mainly connected through dial-up and WiLL technology.

Note: Detail analysis of the projects is not presented in this paper. If required given references could be used to read more information about the selected case studies.

The selected cases were evaluated from the following perspectives:

- User participation: the level of user participation and how user requirements were dealt with.

- User interface/Interaction model: user interface issues related to input and output of information at user and system level were analyzed.

- Technology acceptance: issues concerning technology acceptance and approaches utilized.

- Communication between different stakeholders: ways in which communication between rural user, local stakeholders, and technology providers was established, towards achieving user centric solutions.

- Awareness generation: To analyse the strategies applied to generate project awareness among rural users.

\section{Results}

The preliminary findings from the structured and unstructured interviews and review of the projects revealed few social, community, and design challenges. Issues mentioned under each challenge will be included in the design and development of community sensitive personal health information systems.

\subsection{Social challenges}

Stigmatization: Due to low social status of women in rural India, freedom to express their ideas and problems openly is still a distant dream for rural women and girls [21, 22]. As a result, women with personal hygiene issues mostly do not seek treatment due to existing self and society based stigmatization. Due to embarrassment, women hesitate to discuss their personal health, $[23,24]$. In unavoidable circumstances, they seek treatment from local quacks who are scientifically unqualified for offering health treatments.

Superstition: Owing to superstitions, women are not allowed to visit holy places during their menstruation periods. Additionally, due to lack of exposure, many women think that menstruation is a punishment for some evil doing [25]. 
Trust: It was observed that due to an inefficient formal medical healthcare system there is a high prevalence and trust on traditional medical care practitioner among village women.

Privacy: Low privacy level exists due to existing social norms. In rural India, privacy is curtailed owing to the fact that interaction in public or even private places is often subject to external observation and intervention [26]. This makes women, hesitant in discussing their personal hygiene issues with each other or even to health worker.

Male dominated society: The current study observed that, majority of ICT projects were offering male oriented information. The requirement of several user groups in the rural communities such as village women, adolescent girls, elderly, and youth were ignored perhaps owing to male dominated society $[6,27]$.

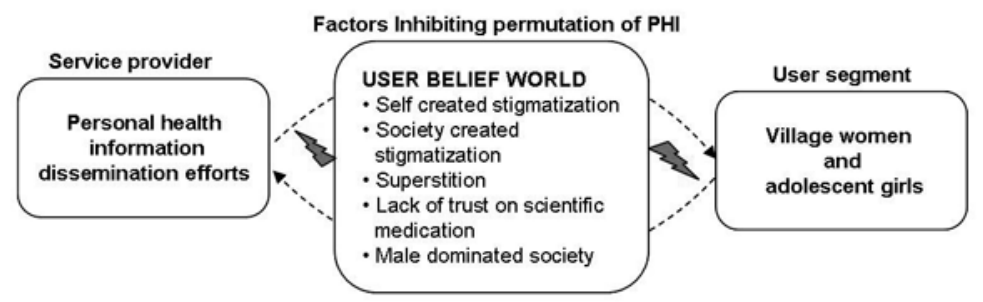

Fig. 2. depicts user belief world inhibiting the permutation of PHI information between information service providers and village women.

\subsection{Community sensitive needs}

Collective capacity building: Existing ICT applications have seldom offered women specific information to improve their social status in the Indian society. There is a need to offer functions, which could develop certain skills or competence to improve their performance ability. With increase efficacy, women could gain dignity.

Collective empowerment: From review it appears that, there are limited ICT applications which addressess women health related issues or have stimulated group participation among village women. Introducing strategies which involve group participation from women could amplify their exposure about new developments. Collective participation may offer opportunity to display their own skill sets in front of other village women, which could strengthen their intra-personal trust.

Collective action: Community cohesions and inclusion are necessary to support community action. Currently there is a need to educate communities as a whole towards having a better understanding of primary health related issues and their basic preventive actions [28]. 
Collective Knowledge sharing: In reviewed cases, it seems that offered ICT application doesn't supports sharing of problems or success stories among rural users at community level. There is a need for a platform where group discussion involving village women could be organized to induce community knowledge sharing.

\subsection{Design Challenges}

Privacy: How to design a system which ensures privacy while receiving information related to personal health issues, while at the same time allow sharing of information at community level.

Trust: There is a low awareness about offered ICT applications among rural users. Low awareness has led to low usage of PHI systems. The challenge is to seek component of design that can play a role in generating awareness about PHI applications and aid in building trust among users.

Attract communities: Given the weak position and the closed mindset of village women in rural communities about sharing personal health issues, the challenge is, to collectively motivate village women to access relevant personal health information and induce community action towards removing existing stigmatization.

Multiple user incorporation: In current ICT projects, there is a limited possibility of disseminating information to multiple users due to close physical environment and limited screen size for offering information. The challenge is, how to present personal health information to multiple users.

Well defined application: Existing ICT projects are mainly focused on providing internet access for web browsing, rather then offering any well defined application. In order to have well defined applications, the challenge is, how users in concern could be involved to generate content and define application and what role design could play to have user participation in early design stages.

\section{Conclusions and proposed research framework}

While formulating information dissemination strategies, seldom have efforts been made towards incorporating existing user social values and beliefs in ICT based PHI systems. As a result, the reacheability and acceptance of current PHI system in rural area have been limited. This has further led to information gap between health service provider and rural users. A study by Guizzardi [29] and Awusabo-Asare [30] demonstrated the persuasive power of ICT and multimedia for providing desired information and training components, without disturbing the social and behavioral patterns of users in developing countries.

While addressing existing social beliefs of rural users and low acceptance issues related to PHI systems, different design strategies will be explored to understand user requirements and develop PHI system. Design strategies would be based on activity organization framework, where process of social change occurs at three stages as mentioned earlier, namely structural, ideational, and skill level [14]. The design propositions will be evaluated via interactive system design variables [31] namely : 
Interactivity: will involve issues related to representation of information to users i.e. audio-visual based, graphic based, or touch based, depending on users skill set. Content: to increase users sense of ownership about PHI system, queries coming from rural users will be included in a content generation process. Later gender specific content could be collected by mapping queries pattern in rural areas.

Form: will include flexibility to offer privacy as desired by the rural users and high observability factors to create awareness about the project.

Strategy: based on existing social system and users belief, several design strategies will be tested as hypothesis.

Connectivity: will consider issues related to knowledge sharing among rural users via intra-personal communication and explore community to community connection via on-line or off-line information.

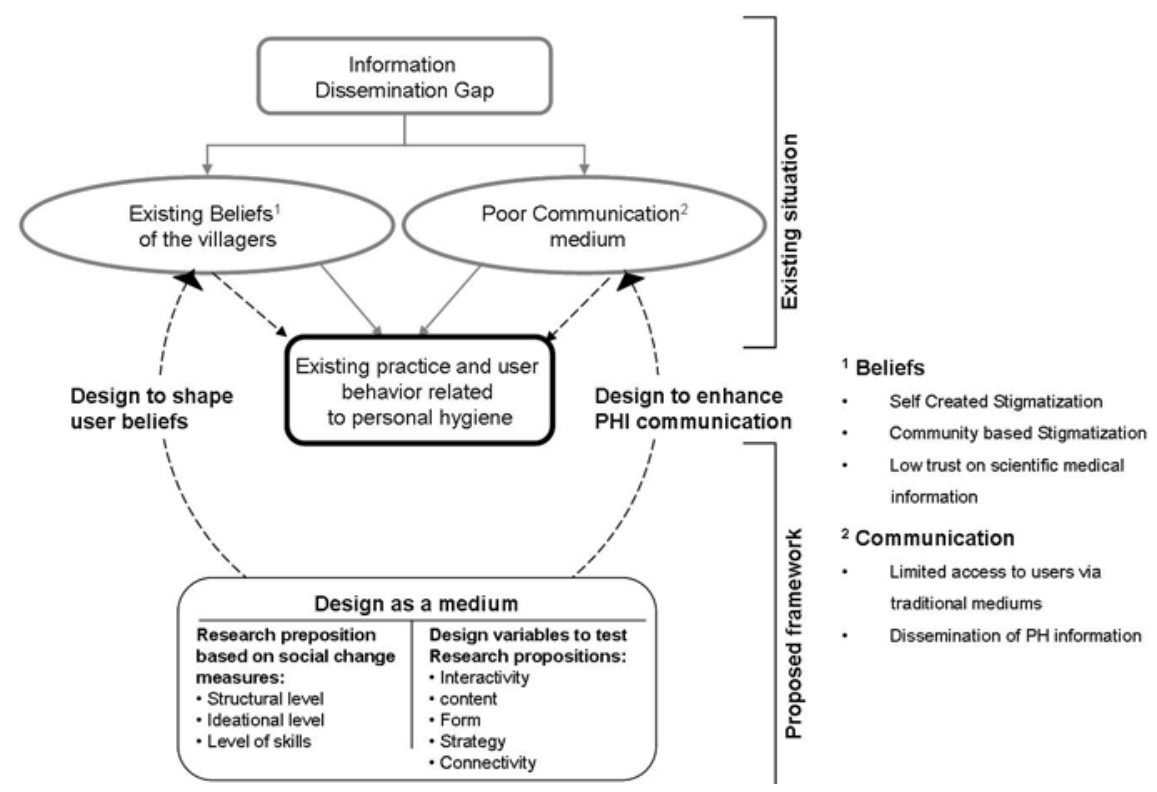

Fig. 3. depicts proposed research through design framework

Interactive system design variable can thus be used as an evaluation factors in the development of a community sensitive PHI system as shown in figure-3. In future, multiple combinations of given design variables will be explored to understand the role of design in development of PHI system. In summary, the result of the current study should lead to the development of integral design methodology and a research platform. This may serve as a tool to extract user requirements, 
incorporating a broad spectrum of factors which may influence technology acceptance. Industries involved in developing and evaluating ICT projects in emerging rural areas, stand to benefit from the expected outcome.

\section{Acknowledgement}

The current research is partially funded by the Smart Surrounding project from the Industrial Design Department, Delft University of Technology. We are thankful to NGO Chetna and Gram seva trust for providing us timely support on the pilot site.

\section{References}

1. Deodhar, N.S., What went wrong with public health in India. Journal of Health and Population in Developing Countries, 2000. 3,: p. 91-98.

2. Mahajan, P. and N. Sharma, Parents attitude towards imparting sex education to their adolescent girls. The Anthropologist, 2005. 7(3): p. 197199.

3. USAID. India's Largest Ever Race Against Diarrheal Deaths 2005 [cited 2005 24th September]; Available from: http://newdelhi.usembassy.gov/pr072706.html.

4. Hirschheim, R.e.a., Information systems development and data modeling: Conceptual and philosophical foundations. 1995: Cambridge \& Aston University Press.

5. Wikipedia. Information system. 2006 [cited 2006 November 14th]; Available from: http://en.wikipedia.org/wiki/Information_system.

6. Raj, H., Rural Sociology. 2005, New Delhi:: Surjeet publications.

7. Spector, Cultural aspects of women's health and health-promoting behaviors. Journal of Obstetrics and Gynecologic and Neonatal Nursing, 1995. 24(3): p. 241-245.

8. Spector, R.E., Cultural diversity in health and illness. 1991, New Jersey: Appleton and Lange.

9. Dourish, P. and K. Anderson, Collective information practice: Exploring privacy and security as social and cultural phenomena. Human-computer interaction, 2006. 21: p. 319-342.

10. Byrne, E. and S. Sahay, Health information systems for primary health care.

11. Metcalfe, M. and C. Joham. The "ear" and "eye" digital divide. in the International Federation of Information Processing IFIP 9.4 and 8.2 Joint Conference on Organizational Information Systemis in the Context of Globalization. 2003. Dordrecht, The Netherlands: Kluwer.

12. Rolland, H.H. and E. Monteiro, Balancing the local and the global in infrastructural information systems. The Information Society, 2002. 18(2): p. 87-100. 
13. Okunoye, A. and H. Karsten, Global access to knowledge: Findings from academic research organizations in sub-Saharan Africa. Information Technology and People, 2003. 16(3): p. 353-373.

14. Kenny, S., Tensions and dilemmas in community development: new discourses, new Trojans. Community Development Journal, 2002. 37: p. 284-299.

15. Yin, R.K., Case study research: Design and methods. 1994: America: Sage publications.

16. Jiva. TeleDoc: Sustainable Healthcare for Rural India. 2005 [cited 2005 April 20th]; Available from: www.jiva.com/health/teledoc.asp.

17. Anantraman, V.e.a., Handheld computers for rural healthcare, experiences in a large scale implementation.

18. Paul, J. What Works: n-Longe's Rural Connectivity Model. 2004 [cited; Available from: http://www.TeNet.res.in.

19. Ponnapa, P.G., IT for common man, in IT for common man (With n-logue). 2004.

20. CEE, Rural cyber cafes on intranet: A cost evaluation study of project Gyandoot, Dhar, Madhya Pradesh, India. 2002, IIM: Ahmedabad,Gujarat.

21. Khanna, A., R.S. Goyal, and R. Bhavsar, Menstrual practices and reproductive problems: A study of adolescent girls in Rajasthan. Journal of health management, 2005. 7.

22. Singh, A., Place of menstruation in the reproductive lives of women in rural north India. Indian journal of community medicines, 2006. 30(1).

23. Bang, R., \& Bang, A, A community study of gynecological diseases in Indian villages in Zeidenstein and Moore (eds.) learning about Sexuality: A Practical Beginning. 1989.

24. Nandini, O., A decade of research on Reproductive Tract Infections and other Gynecological Morbidity in India: What we know and what we don't know Women's Reproductive Health in India, ed. R.a. Jejeebhoy. 2000, New Delhi: Rawat Publication.

25. Deo, D.S. and C.H. Ghattargi, Perception and practices regarding menstruation: A comparative study in urban and rural adolescent girls. Indian journal of community medicines, 2005. 30(Jan- March ).

26. Hofstede, G. Geert HofstedeTM cultural dimension. 2006 [cited; Available from: http:/www.geert-hofstede.com/hofstede_india.shtml.

27. Bharat, S., India: HIV \& AIDS-related discrimination, stigmatization and denial. 2001.

28. Blattman, C., R. Jensen, and R. Roman, A study on assessing the need and potential of community networking for developing countries: A case study from India. 2002.

29. Guizzardi, G. and e.a. Stella R., Rationality and preventive measures: The ambivalence of the social discourse on AIDS. Sexual Interactions and HIV Risk eds. L. V.Campenhoudt, M. Cohen, G. Guizzardt and D. Hausser. 1997. 159 - 180.

30. Awusabo-Asare, K., HIV/AIDS education and counseling: experiences from Ghana. Health Transition Review, 1995. Vol-5: p. 229 - 236. 
31. Benyon, D., P. Turner, and S. Turner, Designing interactive systemsPeople, Activities, Context, Technologies. 2005. 